\title{
The Potential Regressive Role of Syzygium aromaticum on the Reproduction of Male Golden Hamsters
}

\author{
†Donchan Choi, Hyun Soo Roh, Dong Won Kang, and Jong Seok Lee \\ Department of Life Science, College of Environmental Sciences, Yong-In University, \\ Yongin 449-714, Republic of Korea
}

\begin{abstract}
The flower buds of Syzygium aromaticum (clove) have been used as traditional medicine for the treatment of male sexual disorders in Asian countries. Recently, there are some reports about the effects of the clove on reproductive activities in mammals. Therefore, its effect on testicular function was examined in male golden hamsters whose reproductive activity is inhibited by photoperiod such as winter climate. The male animals were given by daily oral administrations (56 consecutive days) in three doses (4 mg, $20 \mathrm{mg}$, and $100 \mathrm{mg} / \mathrm{kg} \mathrm{BW}$ ) of the alcoholic extract of the clove. Generally lower dose $(4 \mathrm{mg})$ of the extract continued to keep the reproductive activities of testes. The both middle and high doses (20 mg and 100 $\mathrm{mg}$ ) of the extract completely inhibited the testicular activity in some animals. Taken together, these results suggest a possible biphasic action of alcoholic extract of Syzygium aromaticum flower bud on testicular function.
\end{abstract}

Key words : Syzygium aromatium, Reproductive activity, Photoperiod, Golden hamster

\section{INTRODUCTION}

Syzygium aromatium (SA) Merr. and Perry. (Myrtaceae) is an evergreen tree $10-20 \mathrm{~m}$ in height indigenous to India, Indonesia, Tanzania, and Sri Lanka. The dried flower bud of the plant is named clove that is reddish-brown in colour and has a strong aroma. In China it has been used for various ailments such as diarrhea, liver and gastrointestinal track ailments, and a stimulant for the nerves (Zhang et al., 2005).

The various activities of the clove represent aphrodisiac, stomachic, carminative, antispasmodic role (Pourgholami et al., 1999). The clove is also reported to have anticarcinogenic property (Zheng \& Kenney 1992; Awad \&
Fink, 2000; Dwivedi et al., 2011). It possesses antiviral activity against Herpes simplex (Kurkawa et al., 1998). Moreover, it is reported to be related to reproductive functions, which leads to preform the present investigation (Mishra \& Singh, 2008).

Reproductive capacity is documented by unique characteristics from species to species. Depending on the ambient climates, animals have developed a particular reproductive strategy. Almost all the animals who inhabit in temperate zone of the Earth show a limited period of the active reproductive function in a year (Choi, 1996). This is plausible for them to save a vast amount of energy required to maintain the active sexual activity. Thus, most of animals reproduce in a proper time in a year, spare the

\footnotetext{
Manuscript received 15 January 2014, Received in revised form 7 February 2014, Accepted 10 February 2014

${ }^{\dagger}$ Corresponding Author : Donchan Choi, Dept. of Life Science, College of Environmental Sciences, Yong-In University, Yongin 449-714, Republic of Korea. Tel : +82-31-8020-2781, Fax : +82-31-8020-2886, E-mail : dcchoi@yongin.ac.kr

This is an Open Access article distributed under the terms of the Creative Commons Attribution Non-Commercial License (http:// creativecommons.org/licenses/by-nc/3.0) which permits unrestricted non-commercial use, distribution, and reproduction in any medium, provided the original work is properly cited.
} 
energy, and keep the species (Choi \& Han, 2010; Choi \& Lee, 2012).

The golden hamster (Mesocricetus auratus) is a small rodent species whose reproductive ability is kept around summer season and regressed in winter (Choi \& Lee, 2012). This seasonal breeding strategy is determined by photoperiod that is the length of lighting in a day, which is surmised that the animal can predict possibly the annual cycle in a period of a year.

The altering changes of seasonal reproductive function in the hamsters can be duplicated in the artificial lighting regime. When the reproductively mature male hamsters are transferred to short photoperiod (SP; equal to and less than 12 hours of lights in a day), they lose generative activities, showing no functional spermatozoa in testes. On the other hand, if the length of lighting in a day is set to more than 12.5 hours of lights (long photoperiod; LP) resembling summer season, the generative functions are energetically resumed, doubtlessly promoted, and maintained afterward.

The goal of the present work was to investigate the effects of the SA extracts on the reproductive activity of male golden hamsters.

\section{MATERIALS AND METHODS}

\section{Plant material and extraction}

The cloves of Syzygium aromaticum were purchased from the local company in Korea (Hyunjin Pharmacy Co., Ltd.). The raw material was ground into powder. The powered cloves $(600 \mathrm{~g})$ were dissolved in $1,000 \mathrm{ml}$ of $60 \%$ ethanol for 10 days. In the process of the extraction, 1,000 $\mathrm{ml}$ of $60 \%$ ethanol was added and the blend was squeezed with woven texture to collect the fluid component. The fluid was evaporated to decoct by warming up the vessel containing the extract in hot water. Then it was dried in the oven kept at $60^{\circ} \mathrm{C}$. The dehydrated product was milled to fine powder by Osterizer blender. The yield of the extract was $10.3 \% \mathrm{w} / \mathrm{w}$ in terms of dried starting material weights. The powered extract was preserved at room temperature and was dissolved with vehicle (drinking water) prior to usage.

\section{Animals}

Adult male golden hamsters (Mesocricetus auratus) were housed in plastic cages under LP conditions of light and dark (light of 14 hours : darkness of 10 hours) with an ambient temperature of $22 \pm 1{ }^{\circ} \mathrm{C}$, assuring that the reproductive activity of these hamsters is always energetic in the photoperiod. They were provided with standard laboratory mouse chow and tap water ad libitum. The condition of management of animals was approved by the Yongin University Institutional Animal Care and Use Committee (YUIACUC-2012-04).

\section{Photoperiod treatment and intubation of the SA}

The golden hamsters were divided into five groups. The control animals were maintained in LP as mentioned above or SP (light of 10 hours : darkness of 14 hours) and received daily the vehicle, which are named as LP or SP, respectively. The experimental animals were housed in SP and treated with the SA extract orally for 56 consecutive days using an intubation needle. They received $4 \mathrm{mg}$ (low concentration), $20 \mathrm{mg}$ (middle concentration), or $100 \mathrm{mg}$ (high concentration) of the SA extract per $\mathrm{kg}$ of body weights on daily basis, named as SPL, SPM, SPH, respectively.

During the entire experimental period the body weights were measured at the interval of 4 weeks. The behaviour of animals was observed to examine any abnormal incidents due to long-term experiment.

The testicular weights were determined at 0,4 , and 8 weeks. Following the measurements of the testicular volumes at the end of treatment, the animals were sacrificed and the testes were isolated and directly weighed. The testicular 
volumes were converted into testicular weights by calculating the major axis and the minor axis via a convenient formula developed previously (Watson-Whitmyre \& Stetson, 1985). The internal organs were also isolated and weighed.

\section{Determination of testes weights}

The testicular volumes were measured by laparotomy. The hamsters were anesthetized using diethyl ether with the aid of pentobarbital ( $25 \mathrm{mg} / \mathrm{kg}$ of body weight) and ketamine $(50 \mathrm{mg} / \mathrm{kg}$ of body weight). The skin overlying the scrotal sac was excised in a proper length, the testes within the scrotal sac were protruded, and the major axis and the minor axis of the testes were snugly measured by vernier calipers. The skin excised was then sutured with surgical thread. The testicular weights were calculated from the measurements. This method reduces greatly the number of animals needed and thus is economic without killing many animals.

\section{Statistical analysis}

Data were expressed as mean \pm SD or mean \pm SEM. Statistical analysis was performed using analysis of variance and student's $t$-test. Differences were considered to be significantat $P<0.05$.

\section{RESULTS}

There were no any particular abnormal behaviors in animals treated with the SA extract for 8 weeks. The change of body weights during the entire experimental period of time was matched with the growth pattern. In general the body weights gradually increased from the beginning of the experiment. No significant differences of body weights were observed among any experimental groups at the end (Fig. 1). Thus, the SA extract was concluded not to affect body weights and not to induce any atypical behavior.

In order to examine any changes of internal organs, various organs were isolated and weighed at the end of the experi-

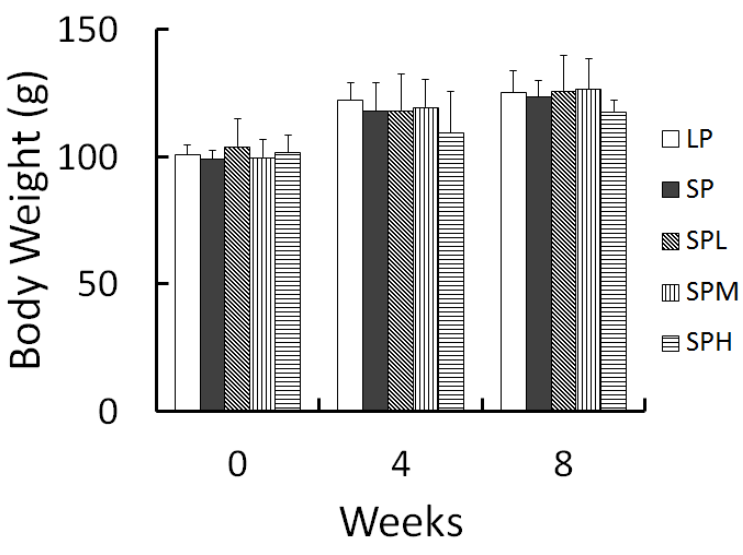

Fig. 1. The body weights of golden hamsters measured at 4 week intervals. They were in general gradually increased throughout the experimental period. LP: animals housed in LP and treated with vehicle, SP: animals housed in SP and treated with vehicle. SPL, SPM, and SPH: animals housed in SP and treated with low, middle, and high concentrations of the SA extract, respectively. Data are represented as the mean $\pm \mathrm{SD}(\mathrm{n} \geqq 6)$.

ment (Table 1). Resultantly no organs were notice-ably altered by the SA extract administration except for the accessory sex organs. The weights of the seminal vesicle and the epididymis were significantly different $(p<0.05)$ in comparison to those in LP.

The changes of testicular weights calculated from the major and the minor axes measured throughout the entire period of experiment are shown in Fig. 2. It has been well established that the testicular mass calculated are direct proportional to the actual testicular weight weighed. To identify the fact the relationship was examined by comparing the values calculated from the measures with the real values weighed. As a result, the real values weighed and the values converted demonstrated a same positive relationship as reported previously (Lee et al., 2013). The outcome implies that the measured values completely bear a close parallel to the values weighed.

At the beginning the weights of testes were about $3.52 \pm$ $0.462 \mathrm{~g}$ (mean $\pm \mathrm{SD})$. The mass of the testes was maintained in LP animals throughout 8 weeks but those in SP animals 
Table 1. Changes of weights of various organs

\begin{tabular}{cccccc}
\hline \hline & LP & SP & SPL & SPM & SPH \\
\hline Heart (g) & $0.58 \pm 0.066$ & $0.62 \pm 0.123$ & $0.54 \pm 0.089$ & $0.60 \pm 0.130$ & $0.53 \pm 0.066$ \\
Lung (g) & $0.65 \pm 0.176$ & $0.64 \pm 0.214$ & $0.82 \pm 0.242$ & $0.78 \pm 0.187$ & $0.70 \pm 0.206$ \\
Spleen (g) & $0.12 \pm 0.021$ & $0.11 \pm 0.015$ & $0.13 \pm 0.037$ & $0.14 \pm 0.044$ & $0.11 \pm 0.008$ \\
Kidney (g) & $0.93 \pm 0.062$ & $0.90 \pm 0.082$ & $0.92 \pm 0.137$ & $0.91 \pm 0.122$ & $0.87 \pm 0.142$ \\
Seminal vesicle (g) & $0.80 \pm 0.229$ & $0.59 \pm 0.164$ & $0.60 \pm 0.137$ & $0.48 \pm 0.195$ & $0.37 \pm 0.152^{*}$ \\
Epididymis (g) & $0.67 \pm 0.072$ & $0.49 \pm 0.105$ & $0.48 \pm 0.082$ & $0.34 \pm 0.187$ & $0.28 \pm 0.185^{*}$ \\
Adrenal (mg) & $32 \pm 5.4$ & $30 \pm 3.6$ & $29 \pm 5.1$ & $27 \pm 5.2$ & $26 \pm 2.1$ \\
\hline
\end{tabular}

LP and SP: animals housed in LP and SP, and treated with vehicle. SPL, SPM, and SPH: animals housed in SP and treated with low, middle, and high concentrations of the SA extract.

Data are represented as the mean $\pm S D(n \geqq 6)$.

* denotes statistically significant difference $(p<0.05)$.

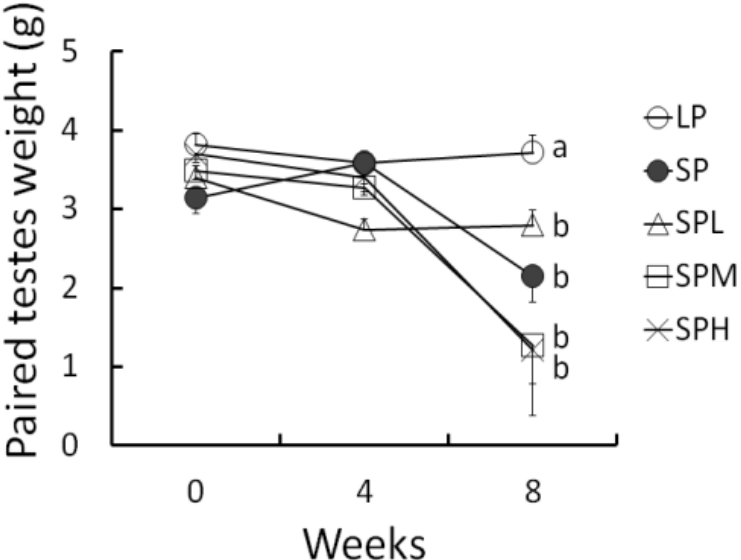

Fig. 2. Changes of testicular weights. The testicular weights of golden hamsters were gauged at 4 week intervals. Note that the only group of animals housed in LP showed statistical significance $(p<0.05)$ with all other groups at the end of experiment. LP: animals housed in LP and treated with vehicle, SP: animals housed in SP and treated with vehicle. SPL, SPM, and SPH: animals housed in SP and treated with low, middle, and high concentrations of the SA extract. Different letters indicate statistical significance $(p<$ $0.05)$. $\mathrm{n} \geqq 6$.

showed distinct decrease in 8 weeks, but not in 4 weeks. The low concentration of SA treatments provoked small decrease of the testes in 4 weeks without any statistical significance, which sustained until 8 weeks of treatment. The resultant masses of the testes in SP and SPL animals were not significantly different. The middle and high concentrations of SA treatments provoked similar effects on reproductive function of the testes in SP animals, with insignificant reduction of the testicular mass due to huge individual variation of testicular weights. By the gross results, LP animals had statistically significant different $(P<0.05)$ testes when compared to the testes of the animals in the other groups.

At the end of experiment ( 8 weeks) the real weights of testes were in fact individually weighed (Fig. 3). The testicular mass was represented by open circle for each animal. The testicular weights were maintained large in LP animals but those in SP animals had largely reduced mass that was significantly different from the LP. The SPL animals in SP had similar size of testes to SP animals. But the animals in both SPM and SPH showed very high variations, resulting in insignificant outcome in statistical analysis. The animals in both groups were divided into two subgroups where one subgroup had testicular weight more than $1.5 \mathrm{~g}$ and the other subgroup had testicular weight less than $1.5 \mathrm{~g}$, as indicated by figure 4 . When compared to the animals in SP group, each middle and high group showed some animals who had large testes and the other animals small testes.

There were apparent individual differences in both SPM and SPH animals at the end of the present experiment. 


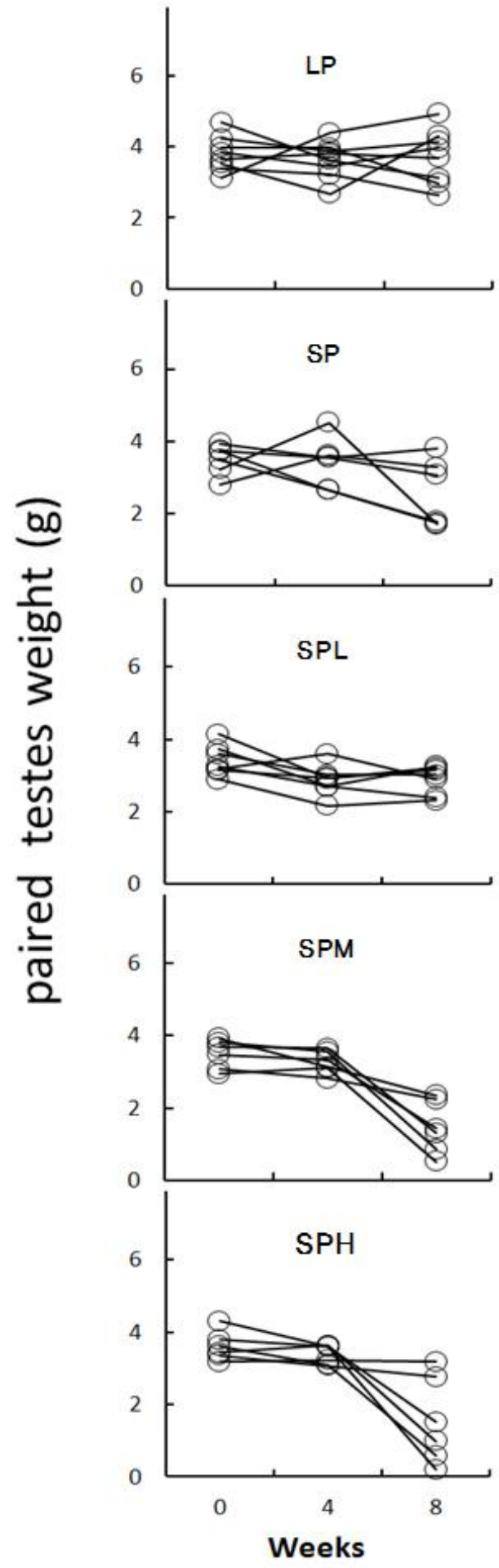

Fig. 3. Changes of testicular weights in individual animals.

LP: animals housed in LP and treated with vehicle, SP: animals housed in SP and treated with vehicle. SPL, SPM, and SPH: animals housed in SP and treated with low, middle, and high concentrations of the SA extract.

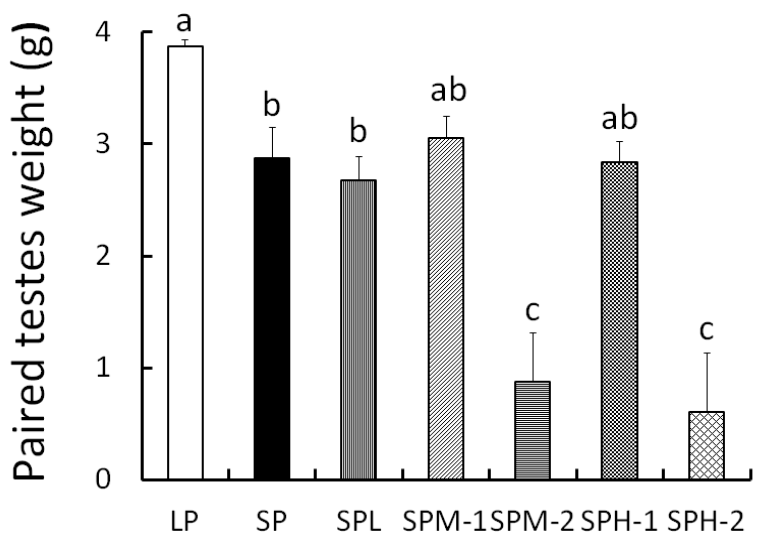

Fig. 4. Changes of actual testicular weights at the end of experiment. Note that the animals in SPM group were divided into two subgroups according to the mass of testes, and were named SPM-1 and SPM-2. The same criteria were applied to the SPH group, and the subgroups were named SPH-1 and SPH-2. LP: animals housed in LP and treated with vehicle, SP: animals housed in SP and treated with vehicle. SPL, SPM, and SPH: animals housed in SP and treated with low, middle, and high con-centrations of the SA extract. $\mathrm{n} \geqq 3$. Different letters indicate statistical significance $(p<0.05)$.

Some animals in both groups showed definitely complete regression of the testes. They are expressed as SPM-2 and SPH-2. The same letter indicates statistically insignificant differences. Some animals assigned to SPM-2 subgroup showed statistically significant difference $(p<0.05)$ to the SPM-1 animals. Similarly, some animals assigned to SPH-2 subgroup showed statistically significant difference $(p<0.05)$ to the SPH-1 animals. The animals received low dose of the SA extract displayed similar results to the SP animals. On the other hand, some animals treated with the middle and the high doses of SA extract showed completely regressed testes, indicative of a further regressing effect of the SP on the testicular function.

\section{DISCUSSION}

The extract of SA used in this study exhibited complete 
inhibition of the testicular activity in some male golden hamsters maintained in SP. The reproductive activity of the animals is usually suppressed by SP, but the sexual activity was not completely involuted by SP because of the shortage of the period of investigation time in the present experiment, resulting in partial regressing effects. The administration of SA led to complete involution in some animals treated with middle and high doses of SA extract. This indicates that the animal was sensitive enough to respond to the dosage of the SA extract administered. To our knowledge, the results are for the first time to show the inhibitory activity of the herbal extract in blocking spermatogenesis in seasonally breeding golden hamsters.

As well-known, the golden hamsters housed in LP have constant large mass of testes that implies functional activity. But SP induces the regression of testes in the animals in period of time of 10 weeks as established previously. It has been documented that the reproductive activity of the animals is regulated by photoperiod. The daylength in summer is more than 12.5 hours, which always promote or sustain the reproductively active function of testes. On the other hand, the daylength of less than 12 hours induces sexual involution in a given time period.

The reason of importance of lengths of daytime or nighttime per day is related to the production of melatonin, which is a major hormone secreted from the pineal gland. The synthesis and release of melatonin is proportional to the length of nighttime, thus melatonin is secreted for expanded period of time in winter, which is considered as an apparent involuting factor on reproductive activity in the golden hamsters. Despite of the imperfect effect of SP on reproduction of the animals, the consequence of complete regression of testes caused by SA extract could be associated with the release of melatonin. That is, SA extract somewhat extended the period of secretion of melatonin leading to involution, although the pattern of melatonin secretion was not examined. If that is the case, the SA extract is thought to indirectly affect the gonadotropin releasing hormone $(\mathrm{GnRH})$ neuronal cells via melatonin to suppress the release of follicle stimulating hormone and luteinizing hormone from the anterior pituitary, which exert their effects on testicular function.

The extraction methods and concentrations used in this study are grossly consistent with those reported previously (Mishra \& Singh, 2008). They used hexane extract of the clove daily up to $60 \mathrm{mg}$ per $\mathrm{kg}$ of body weight of mouse for 5 weeks. They found biphasic action of hexane extract of SA in which lower concentration showed profertility and high concentration antifertility function. Although the extraction method and concentrations used are different, it is intriguing that their results were consistent with the results from the present experiment.

Therefore, the action mechanism of the SA extract could be speculated as follows no matter what animals were used. The SA extract is thought to act on the reproductive endocrine system by exerting its effect on GnRH neuronal cells. The SA extract swallowed by intubation into the body could be absorbed in the gastrointestinal tract and then spreaded all over the body through the circulatory system. As the steroid hormones act on the hypothalamus, some components from the SA extract could act on the hypothalamus, resulting in gonadal regression. Also in the similar manner, they might act directly on the pituitary. It is known that SP reduces the release of $\mathrm{GnRH}$ via the melatonin. Thus the SA extract possibly enhance the action of melatonin, resulting in functional involution of reproductive activity in this animal. Moreover it can be speculated that they affect directly the testes. The components of the SA extract would operate on the Leydig cells to suppress the production of testosterone, and then the reduced amount of steroid influences the spermatogenesis.

On the other hand, it is also not irrational that the ingredients of the SA extract would be converted into another substances by the metabolic process and work on 
the reproductive endocrine system. But it is not yet known which elements of the SA extract operate like those mentioned above. It could be greatly helpful to further examine the hormones in blood and the expression aspects of genes to uncover those action mechanisms.

Phytochemical studies indicate that the clove contains free eugenol, eugenol acetate, caryophyllene, sesqueterpene ester, phenyl propanoid, and $\beta$ caryophyllene (Criddle et al., 2003; Tajuddin et al., 2003; Tanko et al., 2008). However, the compounds had not been scientifically studied for their effect on sexual function. The earlier study using hydro alcoholic extract (50\%) of clove demon-strated the aphrodisiac activity (Tajuddin et al., 2004). Recently, the promoting effect of herbal extract on the reproduction was reported (Lee et al., 2013).

The present investigation represents a potential regressive role of SA extract on the reproductive activity of male golden hamsters. The outcome is based on the reduced testes as well as diminished accessory sex organs such as seminal vesicle and epididymis. But it needs further study for which ingredients have those effects and how they act within the body.

\section{REFERENCES}

Awad AB, Fink CS (2000) Phytosterols as anticancer dietary components: evidence and mechanism of action. J Nutr 130:2127-2130.

Choi D (1996) Reproductive physiology of pineal hormone melatonin. Korean J Zool 39:337-351.

Choi D, Han E-H (2010) The impacts of photoperiods on hypothalamic proteins in the reproductive activities of golden hamsters. Dev Reprod 14:185-197.

Choi D, Lee S-H (2012) Neuroendocrine system in seasonal breeder: focusing on the reproductive activity of male golden hamster. Dev Reprod 16:1-8.

Criddle DN, Madeira SV, Soares de Moura R (2003) Endothelium-dependent and - independent vasodilator effects of eugenol in the rat mesenteric vascular bed. $\mathbf{J}$ Pharm Pharmacol 55:359-365.

Dwivedi V, Shrivastava R, Hussain S, Ganguly C, Bharadwaj Mausumi (2011) Comparative anticancer potential of clove (Syzygium aromaticum) - an Indian spice - against cancer cell lines of various anatomical origin. Asian Pacific J Cancer Prev 12:1989-1993.

Kurkawa M, Hozumi T, Basnet P, Nakano M, Kedota S, Namba T, Kawana T, Shiraki K (1998) Purification and characterization of eugeniine as anti herpes virus compound from Geum japanicum and Syzygium aromaticum. J Pharmacol Exp Ther 284:728-735.

Lee JS, Oh HA, Kwon JY, Jeong MH, Lee JS, Kang DW, Choi D (2013) The effects of Cynomorium songaricum on the reproductive activity in male golden hamsters. Dev Rep 17:37-43.

Mishra RK, Singh SK (2008) Safety assessment of Syzygium aromaticum flower bud (clove) extract with respect to testicular function in mice. Food Chem Toxicol 46: 3333-3338.

Pourgholami MH, Kamalinejad M, Javadi M, Majzoob S, Sayyah M (1999) Evaluation of the anticonvulsant activity of the essential oil of Eugenia caryophyllata in male mice. J Ethnopharmacol 64:167-171.

Tajuddin, Ahmad S, Latif A, Qasmi IA (2003) Aphrodisiac activity of 50\% ethanolic extracts of Myristica fragrans Houtt. (nutmeg) and Syzygium aromaticum (L.) Merr. \& Perry. (clove) in male mice: a comparative study. BMC Complement Altern Med 3:6-10.

Tajuddin, Ahmad S, Latif A, Qasmi IA (2004) Effect of $50 \%$ ethanolic extract of Syzygium aromaticum (L.) Merr. \& Perry. (clove) on sexual behaviour of normal male rats. BMC Complement Altern Med 4:17-23.

Tanko Y, Mohammed A, Okasha MA, Umar AH, Magaji RA (2008) Anti-nociceptive and anti-inflammatory activities of ethanol extract of Syzygium aromaticum flower bud in wistar rats and mice. Afr J Traditional CAM 5:209-212. 
Watson-Whitmyre M, Stetson MH (1985) A mathematical method for estimating paired testes weight from in situ testicular measurements in three species of hamster. Anat Rec 213:473-476.

Zhang CZ, Wang SX, Zhang Y, Chen JP, Liang XM (2005) In vitro estrogenic activities of Chinese medicinal plants traditionally used for the management of menopausal symptoms. J Ethnopharmacol 98:295-300.

Zheng GQ, Kenney PM (1992) Sesqueterpenes from clove (Eugenia caryophyllata) as potential anti carcinogenic agents. J Nat Prod 55:999-1003. 